\title{
Knowledge of Diabetic Foot Care among Nursing Practitioners after Interventional Training in Rivers State, Nigeria
}

\author{
Article by Lilly-West B. R. ${ }^{1}$ Mildred E. John ${ }^{2}$ \\ ${ }^{1}$ Department of Nursing Sciences, School of Nursing, Texila American University, Guyana \\ ${ }^{2}$ Department of Nursing Science, College of Medical Sciences, University of Calabar, \\ Calabar, Nigeria \\ E-mail: buloala2002@yahoo.com
}

\begin{abstract}
Adequate knowledge and consistent practice of specialized diabetic foot care greatly improves the quality of life of diabetics. However, there has been a near absent practice of specialized diabetic foot care observed in health institutions in Rivers State, Nigeria. The study assessed the knowledge of diabetic foot care among 100 nurses in the University of Port Harcourt Teaching Hospital and the Rivers State Hospitals Management Board Hospitals (which include General Hospitals from all the local government areas) in Rivers state, Nigeria before and after interventional training. A one-day hands-on training workshop on diabetic foot care, adopted from the National Institute for Healthcare Excellence (NICE), was implemented to train one hundred (100) nursing practitioners. A structured questionnaire containing questions on different aspects of diabetic foot care was interviewer-administered to the nurses and scored accordingly before and after the training. Knowledge of footwear assessment and assessment of patient's capacity for self-care was found to be significantly low prior to training. There was significant improvement in knowledge of the different aspects of diabetic foot care among the nurses after the intervention. This buttresses the need for formal training of nursing practitioners on diabetic foot care for improvement of the quality of diabetes care in Rivers State, Nigeria.
\end{abstract}

Keywords: Diabetes, Diabetic Foot, Foot Care, Nursing Practitioners, Interventional Training.

\section{Introduction}

Diabetes Mellitus is a non-communicable disease that affects millions globally leading to reduced quality of life and high mortality rates if not properly managed (Soriguer et al., 2012). The prevalence of diabetes in Nigeria, reportedly ranges from $3-11 \%$ throughout the country (Oputa and Chineye, 2015; Uba et al., 2015). In recent times, there has been a rising incidence of diabetes corresponding with increased cost of healthcare, morbidity and mortality (Lim et al., 2012; Mohammed, 2013). Diabetic foot ulcer is a common complication of Diabetes Mellitus which could lead to leg amputations, reduced productivity and reduced quality of life for diabetic patients (American Diabetes Association, 2013). World over, the incidence of Diabetic Foot Ulcers (DFU) is $12-15 \%$ of all patients with diabetes (Saad et al., 2013; Khan et al., 2014). In the United States, diabetes is the leading cause of non-traumatic lower limb amputation. In all diabetics in the US, 5\% of them will develop DFU and $1 \%$ of these will end up with amputation (Chamas et al., 2018). In Nigeria, prevalence of DFU is estimated to be 0.9 - 8.3\% (Akaa et al., 2017). Reportedly, a significant proportion of leg amputations among diabetic patients can be prevented by adopting well-structured preventive management for example; healthy diet, physical activity, the prevention of overweight \& obesity, and extensive foot care (Trepp et al., 2012).

It is evident that nurses have the critical responsibility of providing essential care and information to people living with diabetes to enable them live a quality life $(\mathrm{Hu}, 2011$; Chinenye et al., 2013). The nurse, therefore, must possess the expected knowledge to enable the achievement of this goal. Specialized foot care by nurses in developed countries have recorded considerable success in the prevention of diabetic foot ulcers, prolonging the use of 
the feet of diabetic patients and prevention of amputation (Zarchi et al., 2014). However, it was reported in some developing countries that nurses demonstrated minimal practice of specialized diabetic foot care mostly due to poor knowledge and no substantial training in specialized diabetic foot care (Mohammed, 2013; Umeadi and Chinenye, 2014). The low level of specialized diabetic foot care practice in our setting necessitated the evaluation of nurses' knowledge of diabetic foot care and the subsequent training of nurses on specialized foot care to improve their knowledge. This would subsequently enhance the practice of specialized diabetic foot care thereby improve the health outlook of diabetic patients.

\section{Methods}

\section{Study area}

The study was carried out in the University of Port Harcourt Teaching Hospital (a tertiary health institution), and all the General Hospitals under the Rivers State Hospitals Management Board (secondary health institutions).

\section{Study sample}

A total of 100 registered nurses in the medical and endocrinology clinics who were directly involved in care of diabetic patients for more than 1 year in the hospitals were purposively selected for the study. Participation was voluntary and informed consent was obtained from all nurses, while approval to carry out the study was obtained from the Research Ethics Committees of both the University of Port Harcourt Teaching Hospital and the Rivers State Hospitals Management Board.

\section{Interventional education and training}

After initial interview and observation of foot care practice by the participants, the nurses were trained on specialized diabetic foot care using the National Institute for Health and Care Excellence (NICE) diabetic foot care protocol (NICE, 2015). In the training session, the participants were given materials on diabetic foot care and prevention of diabetic foot ulcer, and also allowed to ask questions.

\section{Data collection}

A 52-item structured questionnaire on specialized diabetic foot care as prepared by Abdullah et al., (2013) was used to assess knowledge prior to and after the interventional training. The questionnaire contained three sections including: Section A: Sociodemographic information of the nurses. Section B: Academic qualifications, years of experience and type of diabetes training received by the nurses. Section $\mathrm{C}$ contained Yes or No responses tailored questions on the knowledge of diabetic foot care in general foot care, Palpation, Auscultation, Footwear Assessment and Assessment of patient's self-care capacity. Each correct answer in the knowledge domain carried 1 mark while Wrong or Don't Know carried 0 mark. This gave a total score range of $0-32$ for knowledge section.

\section{Data analysis}

Completed questionnaire items were analyzed using frequency counts, percentages, means and standard deviation. Responses to the different questions on knowledge of diabetic foot care was collated while scores on each section were graded as follows: The scores in knowledge, attitude and practice domains were categorized as poor (less than and equal to $50 \%$ ), fair (51 to $69 \%$ ) and good (70\% and above) as adapted by Khan et al., (2014). Chi-square was used to test the association between knowledge and academic qualifications among the nurses. Ttest was used to compare the scores in knowledge before and after training. All analysis was done with the Epi Info v7 software at a 95\% confidence interval and a p-value less than 0.05 was considered significant. 


\section{Results}

Table 1 shows the socio-demographic distribution of the study subjects. The mean age of the Nurses was $44.9 \pm 8.9$ years. Among the nurses, 6 (6.0\%) were between $20-30$ years, 34 $(34.0 \%)$, were between $31-40$ years, $30(30.0 \%)$ were between $41-50$ years, $27(27.0 \%)$ were between $51-60$ years and 3 (3.0) were above 60 years. Academic qualifications included; 5 (5.0\%) Basic Diplomas, 51 (51.0\%) Higher Diplomas, 36 (36.0\%) Bachelor's Degree, 6 $(6.0 \%)$ Master's Degrees and $2(2.0 \%) \mathrm{PhD}$. Distribution of the years of practice shows that 6 $(6.0 \%)$ had $<5$ years of practice, $21(21.0 \%)$ had experience between $11-20$ years and $31-40$ years respectively, $22(22.0 \%)$ had experience between $6-10$ years and $30(30.0 \%)$ had experience between $21-30$ years.

Table 1. Socio-demographic Information

\begin{tabular}{|l|l|}
\hline Variable & Frequency $(\mathbf{n}=\mathbf{1 0 0})$ \\
\hline Mean Age $( \pm$ SD) & $44.9 \pm 8.9$ years \\
\hline Age Group $($ years $)$ & \\
\hline $20-30$ & $6(6.0)$ \\
\hline $31-40$ & $34(34.0)$ \\
\hline $41-50$ & $30(30.0)$ \\
\hline $51-60$ & $27(27.0)$ \\
\hline$>60$ & $3(3.0)$ \\
\hline Academic Qualification & \\
\hline Basic Diploma $(\mathrm{RN})$ & $5(5.0)$ \\
\hline Higher Diploma $(\mathrm{RN}, \mathrm{RM})$ & $51(51.0)$ \\
\hline Bachelor's Degree & $36(36.0)$ \\
\hline Masters & $6(6.0)$ \\
\hline PhD & $2(2.0)$ \\
\hline Years of Practice & \\
\hline$<5$ years & $6(6.0)$ \\
\hline $6-10$ years & $22(22.0)$ \\
\hline $11-20$ years & $21(21.0)$ \\
\hline $21-30$ years & $30(30.0)$ \\
\hline $31-40$ years & $21(21.0)$ \\
\hline
\end{tabular}

RN: Registered Nurse, RM: Registered Midwife

Figure 1 shows that 34 (34\%) of the nurses had received training on specialized diabetic foot care before the study was carried and 66 (66\%) had no prior training on specialized diabetic foot care. 


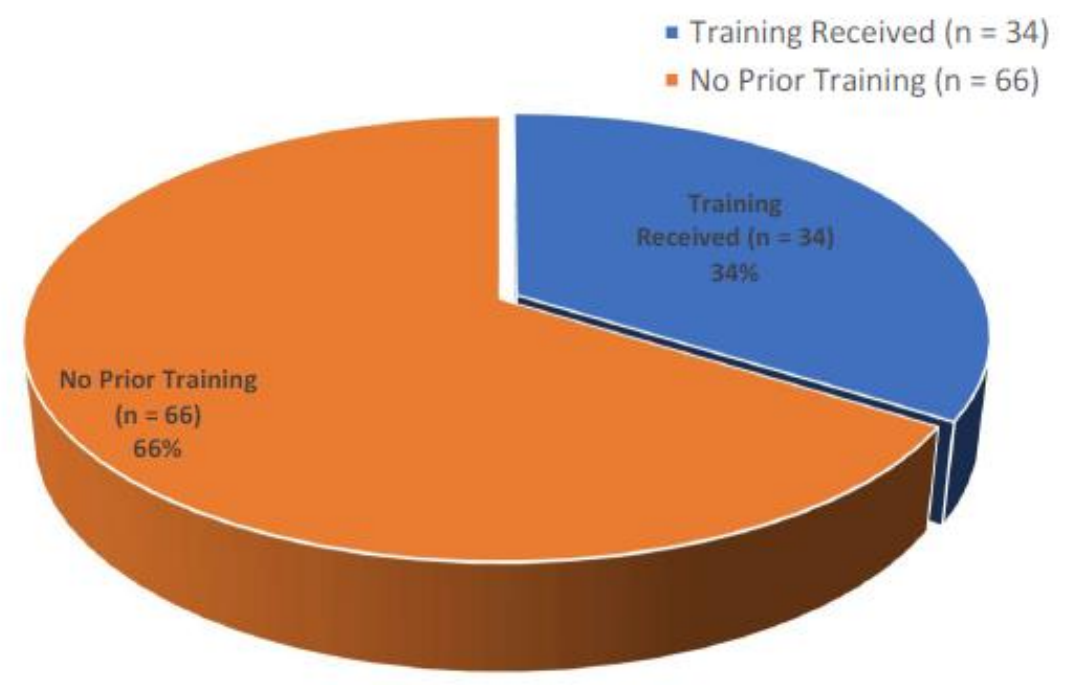

Figure 1: Distribution of prior training recieved on diabetic foot care

Table 2 shows the association of the years of practice and training on specialized diabetic foot care received by the nurses. Two $(5.9 \%)$ of the nurses trained on diabetic foot care had less than 5 years practicing experience, $6(17.7 \%)$ had between $11-20$ years and $21-30$ years of experience respectively, $7(20.5 \%)$ had between 6 - 10 years of experience and $13(38.2 \%)$ had $31-40$ years of experience. There was a significant difference between nurses that have been trained and those that have not been trained which had $31-40$ years of experience $(\mathrm{p}=$ $0.023)$.

Table 2. Cross tabulation of training received on $\mathrm{dm}$ foot care and years of practice

\begin{tabular}{|l|l|l|l|}
\hline & \multicolumn{2}{|l|}{ Training Received } & \\
\hline Years of Practice & Yes & No & Chi-Square (p-value) \\
\hline$<5$ years & $2(5.9)$ & $4(6.1)$ & $0.01(0.9716)^{* *}$ \\
\hline $6-10$ years & $7(20.5)$ & $15(22.7)$ & $0.05(0.8067)^{* *}$ \\
\hline $11-20$ years & $6(17.7)$ & $15(22.7)$ & $0.34(0.5546)^{* *}$ \\
\hline $21-30$ years & $6(17.7)$ & $24(36.4)$ & $3.74(0.0530)^{* *}$ \\
\hline $31-40$ years & $13(38.2)$ & $8(12.1)$ & $9.22(0.0023)^{*}$ \\
\hline & & $\begin{array}{l}\mathbf{6 6} \\
(\mathbf{1 0 0 . 0})\end{array}$ & \\
\hline Total & $\mathbf{3 4 ( 1 0 0 . 0 )}$ & \multicolumn{2}{|l}{} \\
\hline
\end{tabular}

*Statistically significant $(\mathrm{p}<0.05)$; **Not Statistically significant $(\mathrm{p}>0.05)$

The difference in the level of knowledge on diabetic foot care before and after training is presented in Table 3. The results showed that before training, the overall mean score on knowledge was $17.5 \pm 3.6$ and $28.1 \pm 5.5$ after training. The mean score of general foot inspection was $5.5 \pm 1.2$ before training and $6.2 \pm 1.4$ after training. Mean score on diabetic foot assessment was $2.8 \pm 1.1$ and $4.5 \pm 1.6$ after training. On palpation, the mean scores were 1.3 \pm 0.9 and $2.6 \pm 1.3$ before and after training respectively. The mean score on knowledge of Auscultation was $1.6 \pm 0.9$ before training and $2.1 \pm 0.6$ after training. Knowledge of footwear assessment was $1.5 \pm 1.1$ before training and $3.2 \pm 1.5$ after training. The mean score on the assessment of patient's self-care capacity was $1.1 \pm 0.4$ before training and $2.5 \pm 1.1$ after training. 
Table 3. Comparison of Mean scores on Knowledge of Diabetic Foot Care

\begin{tabular}{|l|l|l|l|}
\hline $\begin{array}{l}\text { Sections on DFU care } \\
\text { Knowledge }\end{array}$ & Before Training & After Training & $\begin{array}{l}\text { T-test } \\
\text { (p-value) }\end{array}$ \\
\hline General foot inspection & $5.5 \pm 1.2$ & $6.2 \pm 1.4$ & $0.1268^{* *}$ \\
\hline Diabetic foot assessment & $2.8 \pm 1.1$ & $4.5 \pm 1.6$ & $0.0122^{*}$ \\
\hline Palpation & $1.3 \pm 0.9$ & $2.6 \pm 1.3$ & $0.0003^{*}$ \\
\hline Auscultation & $1.6 \pm 0.9$ & $2.1 \pm 0.6$ & $0.0001^{*}$ \\
\hline Footwear Assessment & $1.5 \pm 1.1$ & $3.2 \pm 1.5$ & $0.0022^{*}$ \\
\hline $\begin{array}{l}\text { Assessment of patient's } \\
\text { self-care capacity }\end{array}$ & $1.1 \pm 0.4$ & $2.5 \pm 1.1$ & $<0.0001^{*}$ \\
\hline Overall score & $\mathbf{1 7 . 5} \pm \mathbf{3 . 6}$ & $\mathbf{2 8 . 1} \pm \mathbf{5 . 5}$ & $\mathbf{0 . 0 0 7 3 ^ { * }}$ \\
\hline
\end{tabular}

DFU: Diabetic foot ulcer.

All figures are presented in' Mean $\pm \mathrm{SD}$,

$*$ Difference is statistically significant $(\mathrm{p}<0.05)$

$* *$ Difference is not statistically significant $(\mathrm{p}>0.05)$

Table 4 shows that before training, $60(60.0 \%)$ of the nurses had good knowledge 25 (25.0\%), had poor knowledge and $15(15.0 \%)$ had moderate knowledge. After training, 80 $(80.0 \%)$ had good knowledge, 12 (12.0) had Moderate knowledge and 8 (8.0\%) had poor knowledge. There was a significant difference in the knowledge before and after training (ChiSquare $=11.95, \mathrm{p}=0.0025)$.

Table 4. Summary of knowledge on diabetic foot care

\begin{tabular}{|l|l|l|l|}
\hline Category & Before Training & After Training & Chi-Square (P-value) \\
\hline Poor & $25(25.0)$ & $8(8.0)$ & \multirow{3}{*}{$11.95(0.0025)^{*}$} \\
\hline Moderate & $15(15.0)$ & $12(12.0)$ & \\
\hline Good & $60(60.0)$ & $80(80.0)$ & \\
\hline Total & $\mathbf{1 0 0}(\mathbf{1 0 0 . 0})$ & $\mathbf{1 0 0 ( 1 0 0 . 0 )}$ & \\
\hline
\end{tabular}

*Difference is statistically significant $(\mathrm{p}<0.05)$

\section{Discussion}

Knowledge of diabetic foot care is crucial in the appropriate practice of diabetic foot care with the aim of improving the quality of life of diabetic patients. Among the nurses sampled, most had higher diploma qualifications ( $\mathrm{RN}$ and $\mathrm{RM}$ ). Only $34 \%$ of the nurses reported to have had prior training on diabetic foot care. A low level of specialized training on diabetic foot care for nurses was identified in this study similar to findings by Ahmed et al., 2011; Trepp et al., 2012; Ali et al., 2015 in middle and low income countries such as Nigeria. In developed countries, it has been reported that specialized training on diabetic foot care among nurses in endocrinology and medical clinics of health institutions is more than 50\% (Ahmed et al., 2011; Trepp et al., 2012; Ali et al., 2015). Before the formal training in this study, prior training was also associated with years of experience as a diabetes care nurse. Nurses with more than 20 years of practice mostly had training on diabetic foot care. This is consistent with the reports of previous studies showing that specialized training on diabetic foot tends to be significantly higher among healthcare professionals with more years of experience especially in developing countries (Trepp et al., 2012; Uba et al., 2015). The observed knowledge on different aspects of diabetic foot care before training among the nurses is consistent with the findings of similar studies, which reported a significant proportion of poor knowledge of diabetic foot care especially among nurses with less years of practicing experience (Ahmed et al., 2011; Rashmi, 2017).

The importance of training was evident in the improved level of knowledge in all aspects observed after training of the nurses as the participants were found to be more knowledgeable 
as reported by similar studies (Drass et al., 2009; Saad et al., 2013; Chammas et al., 2018). Knowledge on footwear assessment was found to be quite poor amongst the nurses prior to training. This is consistent with the findings of the Oyetunde and Famakinwa (2014) which reported significantly poor knowledge and practice of footwear assessment and assessment of patient's self-care abilities, especially among untrained nurses in Ibadan, Nigeria. Footwear assessment and self-care capacity are very significant aspects of prevention of diabetic foot ulcers and eventual amputations among individuals with diabetes (Soriguer et al., 2012; Rashmi, 2017). Also, prior to training knowledge of the nurses on the aspects of Auscultation, Footwear Assessment and Assessment of Patient's self-care capacity was found to be quite low. The marked improvement in the knowledge of the different aspects of diabetic foot care observed in the study are consistent with reports of other studies indicating that training is essential in improving level of knowledge which could positively impact the level of care and quality of life experienced by diabetic patients (Drass et al., 2009; Vileikyte, 2011).

\section{Conclusion}

The study showed a relatively good knowledge of diabetic foot care among the nurses prior to the training. However, specialized training was shown to significantly improve the knowledge of nurses, as trained nurses were shown to have better knowledge of diabetic foot care. However, there was a poor level of knowledge on footwear assessment and assessment of the patients on self-care capabilities. The study showed marked improvement in the level of knowledge on the different aspects of diabetic foot care after interventional education and hands-on training of the nurses. This study has helped in identifying the aspects of diabetic foot care where training needs to be focused on among nursing practitioners in Rivers state.

\section{References}

[1]. Abdullah, W. H., Al-Senany, S., Al-Otheimin, H. K. (2017) Capacity Building for Nurses' Knowledge and Practice Regarding Prevention of Diabetic Foot Complications. International Journal of Nursing Science, 7(1): $1-15$.

[2]. Ahmed, A. A., Elsharief, E., Alsharief, A. (2011) Diabetic foot in the Arab world. The Journal of Diabetic Foot Complications, 3(3): 55-61

[3]. Akogu, I. (2010) The Prevalence of Diabetes mellitus in Nigeria updates and challenges.

[4]. Ali, S. A., Osama A. M., Al-khaldi, Y. M. (2013) Diabetic Patients' Knowledge and Practice Regarding Prevention of Diabetic Foot. Med. J. Cairo Univ., 81(2): 197-205.

[5]. American Diabetes Association (2013). Economic costs of diabetes in the U.S. in 2012. Diabetes Care: 1033-1046.

[6]. Beiranvand, S. Fayazi, S., Asadizaker. M., (2015) Effect of Educational Programs on the Knowledge, Attitude, and Practice of Foot Care in Patients with Diabetes, IOSR Journal of Nursing and Health Science, (4)4 $: 14-20$.

[7]. Chinenye, S., Oko-Jaja, R. I., Young, E. E. (2013). Diabetes and other non-communicable diseases in Nigeria: the need for primary care in the rural setting. Africa Health. 36: 24-7.

[8]. Drass JA, Muir-Nash J, Boykin PC et al (2009) Perceived and actual level of knowledge of diabetes mellitus among nurses. Diabetes Care 12(5): 351-6.

[9]. Hu, F. B. (2011). Globalization of diabetes: the role of diet, lifestyle and genes. Diabetes Care, 34: 124957.

[10]. International Diabetes Federation (African Region)/World Diabetes Foundation. Type 2 Diabetes Clinical Practice Guideline for sub-Saharan Africa. July 2009.

[11]. Lim, S. S., Vos, T., Flaxman, A. D., (2012). A comparative risk assessment of burden of disease and injury attributable to 67 risk factors and risk factor clusters in 21 regions, 1990-2010: a systematic analysis for the Global Burden of Disease Study 2010. Lancet. 380: 2224-60.

[12]. Mohammed, A. H. (2013). Bringing Diabetes Under Control." Bringing Diabetes Under Control. 3 Jan. 2013 EzineArticles.com. 5 Jan. 2013.

[13]. National Institute for Healthcare Excellence (2015) Model of Care for Diabetic Foot. United Kingdom. 
[14]. Oputa, R. N. Chinenye, S. (2015). Diabetes in Nigeria - A translational medicine approach. African journal of diabetes medicine. 23(1):7 - 9 .

[15]. Oyetunde, M. O., Famakinwa, T. T. (2014). Nurses' knowledge of contents of diabetes patient education in Ondo - state, Nigeria. Journal of Nursing Education and Practice, 4(4): 91-98.

[16]. Rashmi, P. J. (2017) A study to assess the knowledge regarding foot care among diabetic patients attending OPD'S at selected hospitals of Lucknow. International Journal of Nursing and Health Science. 3(2): 7-9.

[17]. Schaper, N. C., Apelqvist, J., Bakker, K., (2012) Reducing lower leg amputations in diabetes: a challenge for patients, healthcare providers and the healthcare system. Diabetologia. 55(7):1869-72.

[18]. Soriguer, F., Goday, A., Bosch-Comas, A. (2012). Prevalence of diabetes mellitus and impaired glucose regulation in Spain: The Diabetes Study. Diabetologia. 2012;55(1):88-93.

[19]. Trepp, R., Wille, T., Wieland, T., Reinhart, W. H. (2012) Diabetes-related knowledge among medical and nursing house staff. Swiss Med Wkly. 140(25-26): 370-375.

[20]. Uba, M., Alih, F., Kever, R., Lola, N. (2015). Knowledge, attitude and practice of nurses toward pressure ulcer prevention in University of Maiduguri Teaching Hospital, Borno State, North-Eastern, Nigeria. International Journal of Nursing and Midwifery. 7: 54-60.

[21]. Umeadi M, Chinenye S. (2014). Dietary Management of Diabetes. Lagos, Nigeria: Diabetes Association of Nigeria (DAN), 28-31.

[22]. Vileikyte L (2011) Diabetic foot ulcers: a quality of life issue. Diabetes Metab Res Rev 17: $246-249$.

[23]. Zarchi, K., Latif, S., Haugaard, V. B., Hjalager, I. R., Jemec, G. B. (2014). Significant differences in nurses' knowledge of basic wound management-Implications for treatment. Acta Dermato Venereologica, 94: 403-407. 